This item was submitted to Loughborough's Research Repository by the author.

Items in Figshare are protected by copyright, with all rights reserved, unless otherwise indicated.

\title{
Manual pit emptying as a sustainable livelihood in Ghana
}

PLEASE CITE THE PUBLISHED VERSION

http://dx.doi.org/10.1680/ensu.10.00056

PUBLISHER

(c) ICE Publishing Ltd.

VERSION

VoR (Version of Record)

LICENCE

CC BY-NC-ND 4.0

REPOSITORY RECORD

Nkansah, Andrews, Julie Fisher, and M. Sohail. 2019. "Manual Pit Emptying as a Sustainable Livelihood in Ghana”. figshare. https://hdl.handle.net/2134/10966. 
This item was submitted to Loughborough's Institutional Repository (https://dspace.lboro.ac.uk/) by the author and is made available under the following Creative Commons Licence conditions.



For the full text of this licence, please go to: http://creativecommons.org/licenses/by-nc-nd/2.5/ 


\section{Manual pit emptying as a sustainable livelihood in Ghana}

1 Andrews Nkansah MSC, PhD

Water, Sanitation, Agriculture and Environment Consultant, Loughborough, Leicestershire, UK

2 Julie Fisher MA, PhD

Research Associate, WEDC, Loughborough University, Leicestershire, UK
3 Muhammad Sohail Khan MSc, PhD, Fellow, ASCE Professor of Sustainable Infrastructure, Department of Civil and Building Engineering and Director Research and Enterprise programmes (WEDC), WEDC, Loughborough University, UK
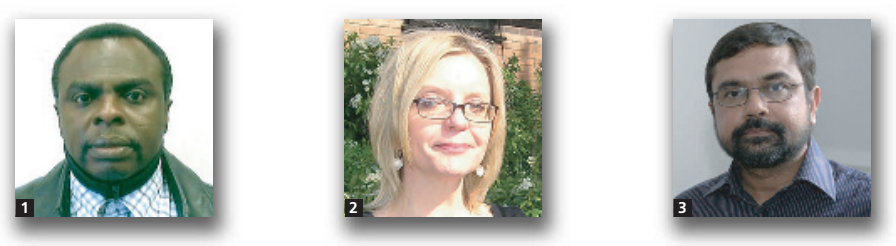

On-plot sanitation is vital in many low-income country urban areas. Pit emptying is critical to its sustainability and small-scale manual emptiers play a key role in this. This paper investigates the sustainability of manual pit emptying as a livelihood option, focusing on the key sustainable livelihood factors relating to the human, social, physical and financial capitals of manual emptiers. These relate to: their role as emptiers; the employment systems and equipment; their health, well-being, social status and the acceptability of the job they do. The paper concludes that the current state of pit-emptying practice does not represent a sustainable long-term livelihood option for manual pit emptiers, as long as it continues with no improvements in technology, insufficient financial incentives and inadequate health and safety measures. Recommendations to improve sustainability include: improvements in emptying technology; provision of subsidies and free medical care; and health and safety education.

\section{Introduction}

The need for safe sanitation has been highlighted in millennium development goal (MDG) 7 on environmental sustainability, of which target 10 is to halve the proportion of people without access to basic sanitation (i.e. the lowest-cost options for safe, hygienic and convenient use) by 2015 (African Sanitation Conference, 2002). The current Who/Unicef joint monitoring programme (JMP) report (Who/Unicef, 2008) reveals that Southern Asia and sub-Saharan Africa regions in particular will not achieve this target unless there is a sharp acceleration in the rate of progress.

Intrinsic to this progress is the provision of improved latrines. These may be flush or pour flush latrines, piped sewer systems, septic tanks, pit latrines, ventilated improved latrines, pit latrines with a slab or composting latrines and bucket latrines. Figure 1 shows a typical example of a commonly used pit.

These are all on-plot or on-site sanitation systems, that is they are contained on a household, housing unit or sanitation system plot, and are dominant in low-income country towns and cities around the world. Strauss et al. (2000) provide figures for the percentage of inhabitants served by on-site sanitation systems in the cities and towns of low-income countries, giving Bangkok (65\%), Ghana (85\%) and Tanzania (more than 85\%) among examples.

This is because conventional sewerage systems are unaffordable and unsustainable (Saywell, 2000; SDC, 2004; Strauss et al., 2000). On-plot sanitation, however, also brings with it a number of problems, mainly regarding the need for regular emptying of pits to allow for their reuse, the constant breakdown of emptying and transport machines and their lack of repair or replacement (Boot, 2007), and poor latrine siting which restricts vehicular access (Ingallinella et al., 2002). For these reasons, manual emptying is the dominant method for consolidated and bulky materials. This involves either: a hauled pan or bucket system, where the pans or buckets used for faecal sludge (FS) storage are emptied there and then into a second bucket to be hauled to the disposal site; or the bucket is hauled to the final disposal site, where it is emptied and then returned; or the practice of digging or scooping such that the FS is removed with simple manual hand tools. 


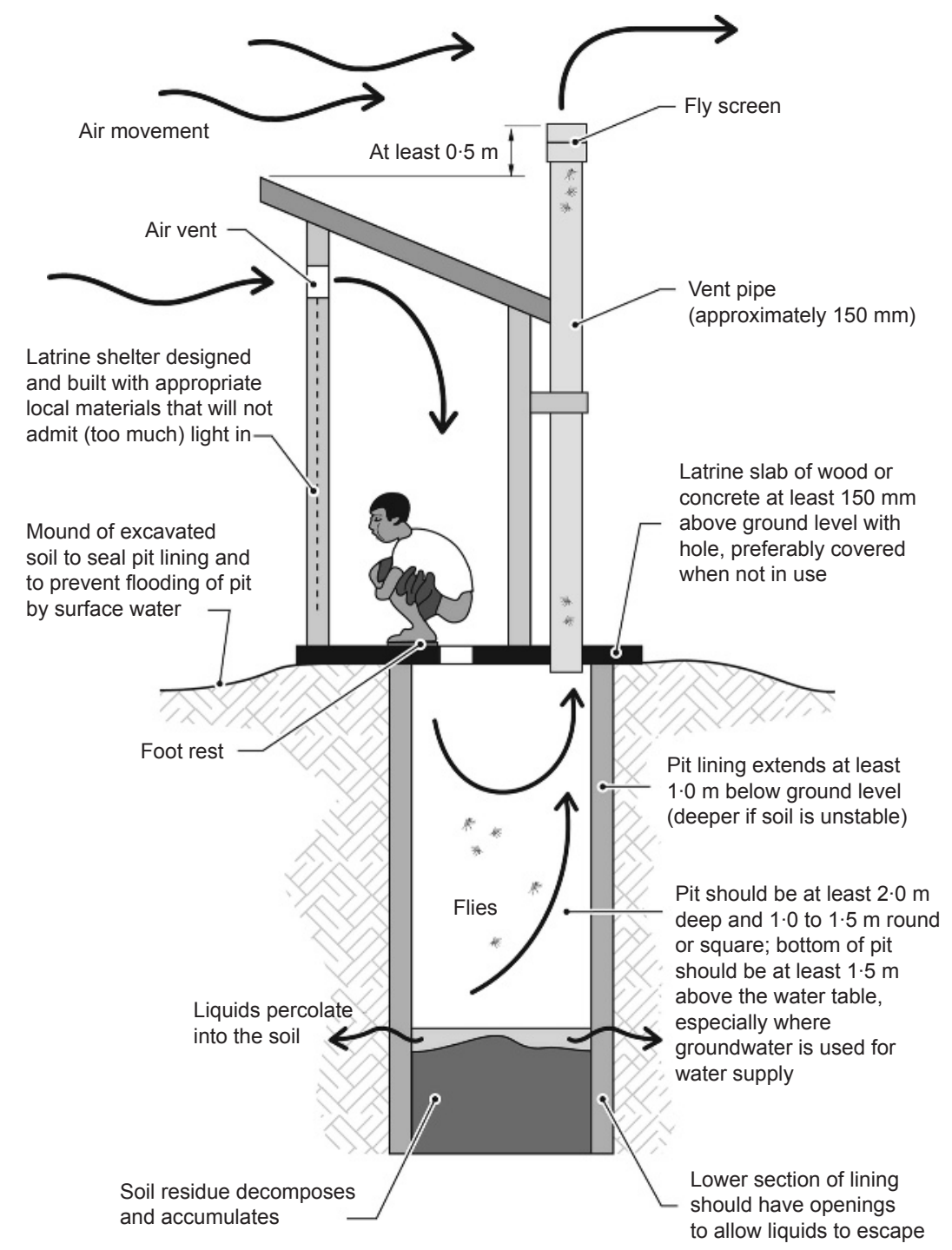

Figure 1. Ventilated improved (VIP) latrine (R. Shaw, WEDC, 2010)

The job of latrine emptier or 'scavenger' exists in many countries. A recent BBC report based on a WaterAid study (WaterAid, 2009) highlighted the adversities suffered by female scavengers of dry pits in India (BBC, 2010). This research focuses on the work of pit emptiers in Ghana, and investigates the real-life experiences of those who perform it and whether the job offers them a sustainable livelihood.

\subsection{Sanitation in Ghana}

Ghana has a total population estimated to be about 20 million, with $44 \%$ residing in urban areas (Ghana Statistical Service, 2001). Sanitation service provision in Ghana is very low and at current rates of progress by the year 2015 the country will have achieved only 26\% coverage (Bussolo and Medvedev, 2007).
Only $4 \cdot 5 \%$ of Ghanaians have access to sewerage systems in some cities (e.g. Accra, Tema and Kumasi) (WSMP, 2008). Therefore, in a country where the majority of latrine users in the cities and towns use on-plot sanitation, pit emptying and bucket collection (from bucket latrines - see Figure 2) play a significant role (Nkansah, 2009; Saywell, 2000; Van der Geest, 2002; WSMP, 2008).

Tamale is the capital and leading economic hub of the northern region of Ghana. However, it is still one of the poorest urban settlements in Ghana (Ghana Statistical Service, 2000) and household sanitation coverage is very low with about $35 \%$ of inhabitants resorting to open defecation (Ghana Statistical Service, 2005). The only sanitation available in the city is on-plot, which is 


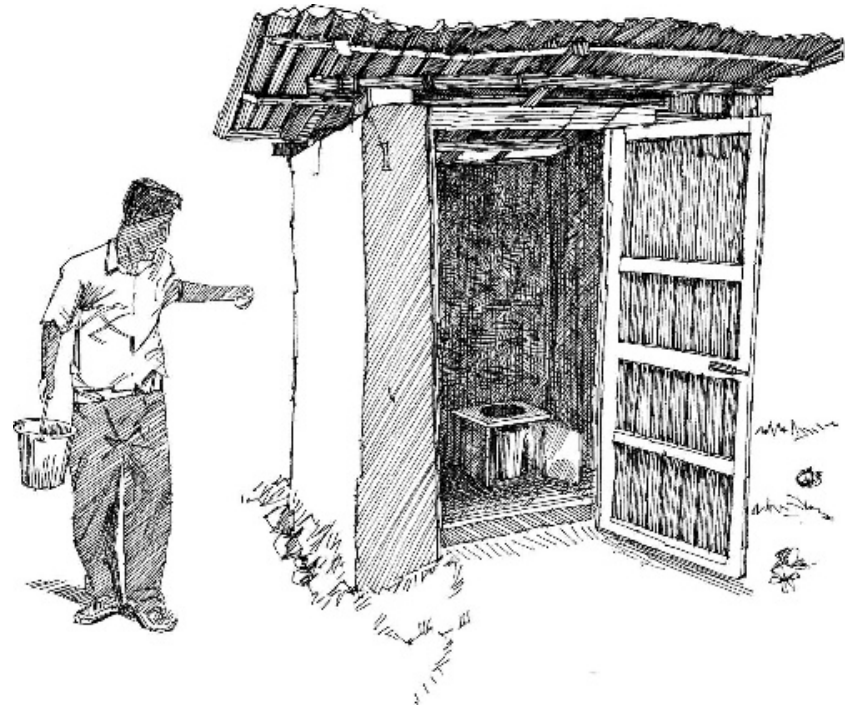

Figure 2. Bucket latrine (R. Shaw, WEDC, 2010)

mainly emptied by small-scale manual operators (Nkansah, 2009). This involves the use of simple tools such as hand-operated pumps, brooms, buckets, drums, scoopers, pickaxes, spades, ladders, ropes, bare or gloved hands and boots (Debomy, 2000; D. Kone, personal communication, 2008).

\section{Methodology and participants}

The original doctoral study on which the current paper is based involved 420 household interviews with respondents in Tamale, Ghana, selected through purposive and random sampling. There were also three focus group discussions with representatives from the communities concerned, and one focus group of six manual pit emptiers. Six key municipal waste management officials were also interviewed concerning their views and experiences of the management of pit-emptying services. In addition, personal observation was carried out on various types of latrines used, looking at the materials put into the pits, the level of difficulty of latrine emptying, the injuries incurred with manual pit emptying, and the collection and disposal of bucket contents.

\section{The sustainable livelihoods approach and manual pit emptying}

Chambers and Conway (1992) describe the sustainable livelihood concept as the capabilities, assets (both material and social resources), and activities required for a means of living. A livelihood is sustainable when it can cope with and recover from stresses and shocks, and maintain or enhance its capabilities and assets both now and in the future, while not undermining the natural resource base. In view of this, Serrat (2008) suggests a sustainable livelihood framework of human, social, natural, physical and financial capital assets.
In the context of urban pit emptying, in relation to small-scale manual emptiers, this framework is transposed as follows: there needs to be sufficient pits (physical capital) for emptying by the emptiers (human capital); the emptiers should also have a high enough level of social support and morale (social capital), as well as the capacity and assets (human and physical capital) to empty the pits successfully and continuously. This should provide sufficient income (financial capital) for their livelihood now and in the future without jeopardising their health (human capital).

Several studies acknowledge the important role of small-scale enterprises and emptiers in the pit-emptying market (Bongi and Morel, 2005; Eales, 2005; Nkansah, 2009). Bongi and Morel (2005) describe the Kibera manual pit emptiers in Kenya, who are faced with the constant threat of injury and infection from the pit contents and working without protective gear; they are harassed by groups of youths, stigmatised by society and ignored by public officials. Also Eales' (2005) case study on manual emptiers in Kenya reveals that despite the importance of their work, little value is attached to their service by members of the communities they operate in. She confirms Bongi and Morel's findings that they work without simple protective clothing and receive very low payment. However, in the case of Durban, South Africa, Eales witnessed a positive interaction between the service users and pit emptiers, who are provided with the protective clothing they need. Here, the eThekwini municipality acknowledges the value and importance of the emptiers and provides a substantial subsidy to ensure a good service at no cost to households. None of these authors, however, discuss in depth the factors affecting the livelihoods of these small-scale manual pit emptiers.

\section{Findings}

The findings are organised around the different capital assets of the livelihoods framework approach.

\subsection{Human capital: "We work as a team"}

When a pit is full, the latrine owner will inform an emptier of this. The emptier then calls in more of his colleagues: 'We, the emptiers, know ourselves. We are usually friends from the same tribe so when one of us gets information about emptying he informs two or more other friends to assist in the emptying.' This type of employment is communicated through informal means and existing peer contacts. There appear to be no formal advertising procedures.

The size of the team is a minimum of two people for a household pit, but can be up to five people for a public latrine, A team can include both men and women, although they may not carry out the same tasks or be equally rewarded. Emptying is mainly the job of men using simple hand tools (see Figure 3) and is described in the following quote: 


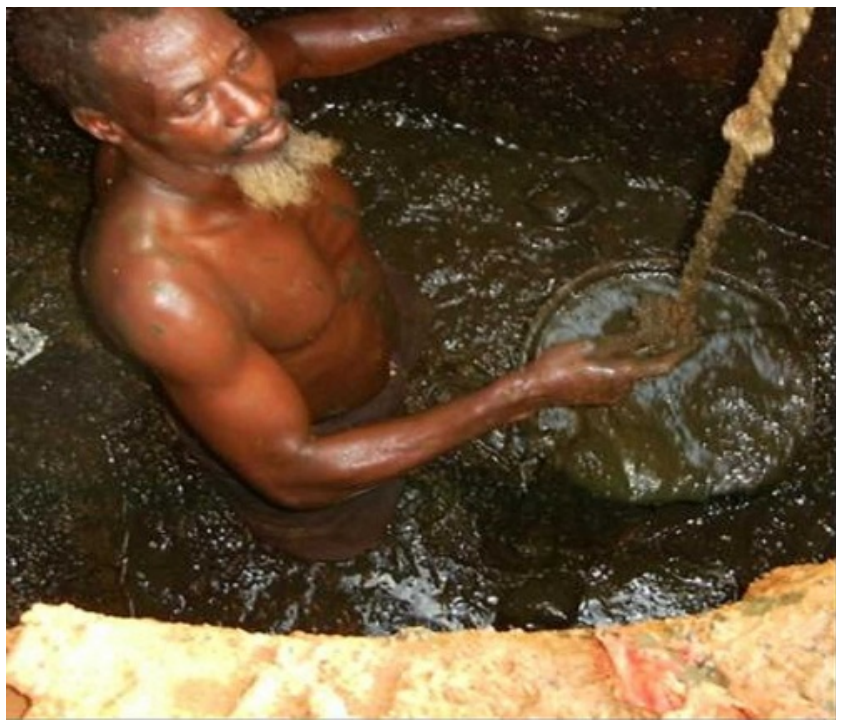

Figure 3. Example of a manual pit emptier immersed in a pit (D. Kone, personal communication, 2008)

One of us gets into the pit through an inserted ladder to dig and or collect the faecal matter and other non-faecal stuff into a ropesupported bucket which is then pulled by one or two persons at the top of the pit for disposal. In a team of two persons, there is exchange of service between the two - when exhausted, a digger inside the pit will come up to replace the collector on the top of the pit who then descends into the pit to replace the first digger. This continues till the job is done. With deeper and longer pits like the public latrines, the size of the team becomes bigger. In this case, two or more diggers can go inside the pit to dig and collect the faecal matter while the rest will stand on top of the pit to collect the emptied stuff.

Women's role is restricted to cleaning the mess left after emptying. The wife of a caretaker of a household latrine complains that: 'Sometimes we the women clean so much mess left by these emptiers, but unlike the emptiers we are not paid for cleaning the mess that is left over. This is annoying and disgusting!'

The interviews and observations about the modus operandi for bucket latrine collection and pit emptying reveal the need for sustaining teamwork if the job is to be carried out effectively.

\subsection{Financial capital: 'I have been emptying pits for long time, yet I am still very poor"}

A participatory work ethos means that the earnings are spread very thinly between several people which does not provide a living wage: 'Pits are not full everyday and these days emptiers are many so when we share the job, the money is insufficient to take care of us fully.'
Retired municipal employees, because of their experience and expertise, are hired to empty the public latrines to supplement mechanical emptying. These workers were retired from regular service as there were insufficient funds to offer them regular salaries. This means they compete for pit emptying with other small-scale pit emptiers. One retired employee complained: 'I do not earn as much as I used to when I was a regular employee at the municipality. I am only called when I am needed to assist in pit emptying. I am worried about my future. Many new emptiers have now joined the emptying market.' This comment reveals that emptiers are clearly concerned about the threat to their livelihoods posed by their increased numbers.

The charge for emptying is not set at a standard rate, but negotiated with each household or latrine owner. 'The emptying price is bargained by all of us. After agreeing to the price with the latrine pit owner, we then empty the pit first before we are paid.' However, the rate of pay is low for this work. Comments include: 'I always pray that we get more work to do so that I can get enough to cater for my family,' and 'Depending on the pit size and number of jobs available, each pit emptier can earn about \$20 per month.' Bucket latrine emptiers can earn slightly more: 'Collection and disposal of one bucket latrine is about $\$ 0 \cdot 50$.' In the study area, an average household needs two bucket collections a week, which would cost them $\$ 4.00$ per bucket latrine per month. A bucket collector emptying excreta from ten households a day can earn about $\$ 40$ a month, which is twice the average amount earned by a pit latrine emptier. However, comparisons with Ghana's national median monthly earnings index by Nsowah-Nuamah et al. (2009) shows that manual pit and bucket emptiers are at the lower end of the income index.

Interviews with respondents reveal that their income depends on the type, contents and number of pits emptied. Pits that attract the highest earnings are those that are deep and contain other materials in addition to faecal matter, such as metals, wood and plastics (Figure 4). According to the municipal officials interviewed, the conventional emptying machines are not able to siphon these hard materials out of the pits. The manual emptiers are the sole agents capable of doing this. Interviews show that a large public latrine employing up to five emptiers can attract a charge of about $\$ 250$, while household latrines using two emptiers costs about $\$ 60$ to empty. All the monies accrued belong to the emptiers.

Many pit emptiers supplement their pay with other work, to try to make a living wage. Comments include: 'I supplement pit emptying with other menial jobs in order to get enough money to make ends meet' and 'I also do bucket latrine collection to supplement pit emptying.' Other manual emptiers confirm that 


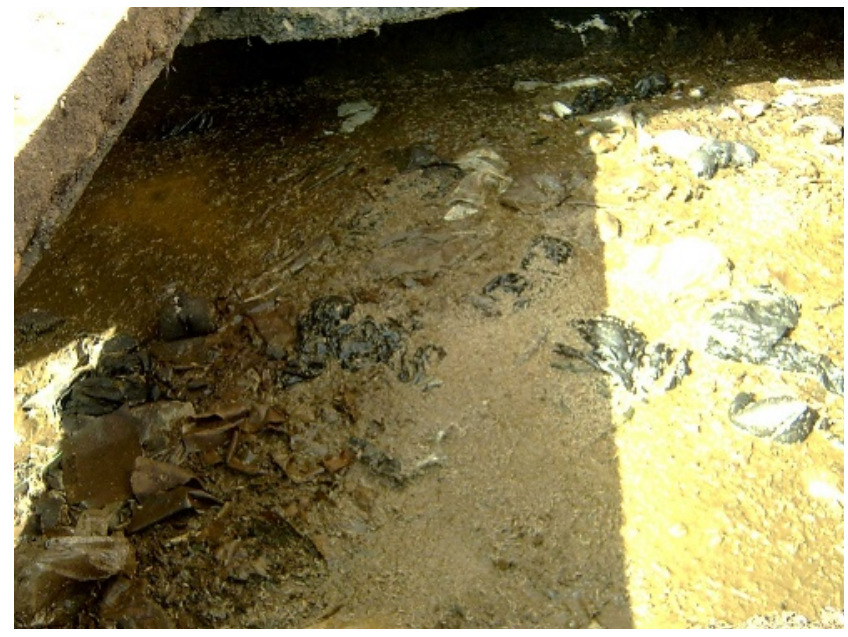

Figure 4. Vault filled with excreta and other materials (Nkansah, 2009)

additional menial jobs are taken on, including gardening, farm labouring and carting goods.

Pit emptying is an irregular and unpredictable source of income. It requires teamwork, which means that earnings are necessarily shared. The increasing level of competition for work is another serious challenge to its sustainability as a source of income.

\subsection{Physical capital: 'Rudimentary tools like buckets, spade, and pickaxe"}

Field observations and other interview data confirm that common tools include: a ladder; a long stick (to measure the depth of the faecal matter to be emptied); a bucket with an attached rope (to collect faecal matter from inside the pits to the top of the pit); a pickaxe (to dig out consolidated faecal matter at the bottom); and a spade or shovel to collect the faecal matter and other non-faecal material (pieces of metal, wood, etc.) into a bucket for disposal. In the case of the shallow pits (less than $1 \mathrm{~m}$ deep), the spade or shovel is used to dig out the faecal matter and throw it directly onto the surface. Wellington and ordinary boots as well as gloves are sometimes used, although there were visible signs of wear and tear in these which allowed direct bodily contact with faecal matter. Masks and helmets are not used.

An emptier complained that the tools are too basic and hinder their efficiency and do not protect against contact with faecal matter. There is the need to provide improved tools and equipment for manual emptying in order to increase efficiency and to avoid bodily contact with excreta.

\subsection{Human capital: 'Public and private pits where all sorts of dangerous materials are put into them by the users"}

There are many significant health and safety risks associated with manual emptying which affect its potential for livelihood sustainability. The buckets lack handles and emptiers have to lift them with both hands, usually without gloves, inevitably coming into direct contact with faecal matter. The lack of protective clothing, the degree of stench and the close contact with excreta are graphically represented in an extract from the authors field work diary on the observation of bucket latrine collection and disposal in Tamale

I met Zeba at about 1 a.m. at a designated meeting place. He was carrying on his head an empty pan while holding in his hand a torch light. He was wearing a pair of sandals, shorts and some tattered shirt. Upon reaching his first bucket to be emptied, he put down the bucket he was carrying, lit the torch light in the direction of the bucket latrine and opened the door leading to the bucket filled with human excreta. Immediately he opened the door the obnoxious smell of the excreta was very intense. I spat several times while Zeba did not show any sign of abhorring the stench. He then put the torch, still lit, down so that he could use the two hands without gloves to pull the bucket out. He poured the contents of the bucket into his own pan, and walked to a distance of about 50 metres from the collection point and dumped the contents into a shallow trench. I asked whether he would cover it and he said he would do so after adding more from the neighbourhood. (Source: authors' field observation, 2007 - see Figure 5.)

At one emptying site, objects such as pieces of metal, sandals, wooden planks, nails, pieces of broken bottle, plastic bags and



Figure 5. Bucket latrine, Tamale, Ghana (Nkansah, 2009) 
rags were observed in the emptied material. A range of potential health impacts exist from direct injuries (due to sharp objects) to infections from pathogens: 'Some sharp objects injure us and make us ill. We also get sick frequently with all kinds of ailments including headaches, stomach aches, nausea, vomiting and skin rashes.'

Manual emptiers of deep pits (more than $1 \mathrm{~m}$ ) said that illness and injury is caused by the excessive heat and dangerous objects in the pits. This is exacerbated by their close proximity to the pit and the use of rudimentary tools which impede progress. An emptier revealed scars and wounds on his body which he said were due to burns and injuries from heat and from objects found in the pits. Comments from other emptiers confirm that that they suffer from frequent nausea, vomiting, headaches, stomach aches, skin rashes, diarrhoea and dysentery.

However, the municipal officers interviewed confirmed that there were no official health and safety measures for emptying and handling faecal matter. Infections and injuries suffered increase the costs incurred by emptiers, who need to buy drugs and other medical treatments.

Another emptier reports that: 'The stench is so much that we make sure we eat enough before emptying so that we do not have in-between meals. We also drink 'hot' (strong) alcohol to help us overcome the stench and nastiness.' This is an unrefined locally brewed drink with $60-70 \%$ of alcohol. Observations and personal meetings strongly suggested that some pit emptiers were suffering from the effects of excessive alcohol.

The injuries, illnesses, drunkenness and its associated weakness, as well as the consequent expenditure on drugs and hospital treatment, detract from the possibility of this job providing the emptiers with a sustainable livelihood. The provision of medical subsidy could assist emptiers to meet the health needs resulting from their work.

\subsection{Social capital: "People should respect us'}

Manual emptiers are stigmatised in the communities in which they live. Derogatory songs are sung about them which reinforce the low esteem in which they are held. An emptier remarks that:

\footnotetext{
It is difficult for us to have girlfriends or wives from the community because of our job. Women do not want to be associated with us. Even the wives and the children of the married ones among us are not free from the derogatory remarks. As a matter of fact, the general public avoids us. This makes us feel so bad and pushes us to look for alternative jobs.
}

Emptiers are often uncomfortable at public gatherings because they and their families are socially excluded and not accepted by the community: 'Me, my wife and children are called many derogatory names. As a result of this we sometimes feel shy to mingle with many people.'

Although the job of pit emptier is a vital activity which benefits the lives and health of the whole community, the social consequences for those who perform the task are harsh. In terms of a sustainable livelihoods framework, social capital assets are severely constrained by working as a pit emptier. Respondents' experiences suggest that the public should be educated to understand the important role of the manual emptiers and respect them for it.

\section{Conclusions}

In spite of the importance that manual pit emptying plays in urban sanitation and in providing an income for the emptiers, there are very few studies relating to this. This research has considered the sustainable livelihood assets that apply to pit latrine emptiers. Their 'vulnerability context' (Serrat, 2008) or insecurities as individuals and members of households is high and relates to shocks owing to the risk of illness and disease, seasonalities of price and varying employment opportunities. These factors severely constrain their livelihood opportunities.

Current pit-emptying practice uses very basic tools and lacks the necessary modifications and improvements in emptying technology. It also lacks sufficient financial incentives for both emptiers and users to sustain the industry, as well as any effective health and safety measures. The authors therefore conclude that without addressing these issues, manual pit emptying will remain unsustainable as a means of earning a livelihood in Tamale, Ghana.

To address this, the onus has to be on the government or municipal authorities (and other relevant benevolent organisations) to assist the manual emptiers to develop their capacity in terms of skills and equipment for more efficient emptying. This in turn has the potential for significant impacts on improving their health and well-being, their efficiency as pit emptiers, and therefore the level of profit they can make, which would enable them to better cover their capital and operational costs to sustain the industry. It is recommended that the following recommendations are adopted by the agencies identified above:

provision of effective tools and equipment, and improvements in any manual emptying technology, in order to increase emptying efficiency and to avoid bodily contact with excreta

- subsidies for equipment to improve service and medical care to meet the health needs resulting from this work

health and safety education to manual emptiers to help them avoid emptying dangers and contamination. 


\section{REFERENCES}

African Sanitation Conference (2002) Conference Statement on Sanitation and Hygiene in Africa. See http://www. genderandwater.org/page/806 for further details (accessed 20/08/2006).

BBC (2010) India's Scavengers. 10 November 2010. See http:// news.bbc.co.uk/today/hi/today/newsid_9170000/9170912. stm for further details (accessed 10/11/2010).

Bongi S and Morel A (2005) Understanding Small Scale Providers of Sanitation Services: A Case Study of Kibera. Kenya. Water and Sanitation Program, Washington DC, USA.

Boot NLD (2007) Talking Crap: Faecal Sludge Management in Accra, Ghana. MSc thesis, WEDC, Loughborough University, Loughborough, UK (unpublished).

Bussolo M and Medvedev D (2007) Challenges to MDG Achievement in Low-Income Countries: Lessons from Ghana and Honduras. World Bank, New York. Policy Research Working Paper 4383.

Chambers R and Conway GR (1992) Sustainable Rural Livelihoods: Practical Concepts for the 21st Century. Institute of Development Studies, Brighton, UK. Discussion Paper 296.

Debomy S (2000) Commercial Solid Waste Collection by Nightsoil attendants in Kano, Nigeria. Water Utilities Partnership Project 5. 2000. See http://web.mit.edu/urbanupgrading/ waterandsanitation/resources/examples-pdf/ ComNightSoilCollection-NG.pdf for further details (accessed 12/11/10).

Eales K (2005) Sanitation Partnerships Series: Bringing Pit Emptying Out of the Darkness: A Comparison of Approaches in Durban, South Africa, and Kibera, Kenya. Building Partnership for Development in Water and Sanitation, London, UK.

Ghana Statistical Service (2000) Poverty Trends in the 1990s. Ghana Statistical Service, Ghana.

Ghana Statistical Service (2001) 2000 Population Census of Ghana, Ghana Statistical Service, Ghana.

Ghana Statistical Service (2005) 2000 Population and Housing Census. Analysis of District Data and Implications for Planning. Ghana Statistical Service, Northern Region, Tamale, Ghana.

Ingallinella AM, Sanguinetti G, Koottatep T, Montangero A and Strauss M (2002) The challenge of faecal sludge management in urban areas - strategies, regulations and treatment options. Water Science and Technology 46(10): 285-294.

Nkansah A (2009) Management of Faecal Sludge in the Urban Areas of Low-income Countries: A Case in Tamale. PhD thesis (unpublished, WEDC, Loughborough University), Loughborough, UK.

Nsowah-Nuamah N, Awoonor-Williams M and Teal F (2009) Jobs and Skills in Ghana: What types of jobs have been created and where? Paper presented at UKFIET Oxford International Conference on Education and Development, 15-17 September 2009. Centre for the Study of African Economies, Department of Economics University of Oxford, Oxford, UK.

Saywell D (2000) User Based Perceptions of On-plot Sanitation Systems in Low-income Urban Communities in Africa and Asia. PhD thesis, WEDC, University of Loughborough, Loughborough, UK (unpublished).

SDC (Swiss Agency for Development and Cooperation) (2004) Sanitation is a Business - Approaches for Demand-oriented Policies. SDC, Switzerland.

Serrat O (2008) The Sustainable Livelihood Approach. Knowledge Solutions. Asian Development bank (ADB). See http://www.adb.org/Documents/Information/ Knowledge-Solutions/Sustainable-Livelihoods-Approach. pdf for further details (accessed 25/08/2010).

Strauss M. Heinss U and Montangero A (2000) On-site sanitation: when the pits are full - planning for resource protection in faecal sludge management. Proceedings of an International Conference, Bad Elster, Schriftenreihe des Vereins fuer Wasser-, Boden und Lufthygiene, 2000; 105: 353-60: English title: Water, Sanitation and HealthResolving Conflicts between Drinking Water Demands and Pressures from Society's Wastes (I. Chorus, U. Ringelband, G. Schlag and O. Schmoll (eds)). IWA Publishing House and WHO Water Series.

Van der Geest S (2002) The night-soil collector: bucket latrines in Ghana. Postcolonial Studies 5(2): 197-206.

WaterAid (2009) Burden of Inheritance: Can We Stop Manual Scavenging? Yes, But First We Need to Accept it Exists. WaterAid, India.

WHO and UNICEF (World Health Organization and United Nations Childrens' Fund) (2008) Progress on Drinking Water and Sanitation: Special Focus on Sanitation. UNICEF, New York; WHO, Geneva.

WSMP (Water and Sanitation Monitoring Programme) (2008) Use of Toilet Facilities in Ghana: Can the country achieve $M D G$ f for sanitation? WSMP, Accra. WSMP report.

\section{WHAT DO YOU THINK?}

To discuss this paper, please email up to 500 words to the editor at journals@ice.org.uk. Your contribution will be forwarded to the author(s) for a reply and, if considered appropriate by the editorial panel, will be published as discussion in a future issue of the journal.

Proceedings journals rely entirely on contributions sent in by civil engineering professionals, academics and students. Papers should be 2000-5000 words long (briefing papers should be 1000-2000 words long), with adequate illustrations and references. You can submit your paper online via www.icevirtuallibrary.com/content/journals, where you will also find detailed author guidelines. 